Article

\title{
Definition of Optimal Ventilation Rates for Balancing Comfort and Energy Use in Indoor Spaces Using $\mathrm{CO}_{2}$ Concentration Data
}

\author{
Alessandro Franco * (D) and Eva Schito \\ Department of Energy, Systems, Territory and Constructions Engineering (DESTEC), University of Pisa, \\ Largo Lucio Lazzarino, 56122 Pisa, Italy; eva.schito@for.unipi.it \\ * Correspondence: alessandro.franco@ing.unipi.it
}

Received: 12 June 2020; Accepted: 22 July 2020; Published: 24 July 2020

check for updates

\begin{abstract}
Air ventilation rate plays a relevant role in maintaining adequate indoor air quality (IAQ) conditions in public buildings. In general, high ventilation rates ensure good indoor air quality but entail relevant energy consumption. Considering the necessity of balancing IAQ and energy consumption, a correlation between the number of occupants obtained from analysis of $\mathrm{CO}_{2}$ concentration variation is presented as a general element for controlling the operation of heating ventilation and air cooling (HVAC) systems. The specific $\mathrm{CO}_{2}$ exhalation rate is estimated using experimental data in some real conditions in university classrooms. A method for the definition of optimal values of air exchange rate is defined, highlighting that the obtained values are much lower than those defined in current technical standards with possibilities of relevant reduction of the total energy consumption.
\end{abstract}

Keywords: indoor air quality (IAQ); $\mathrm{CO}_{2}$ production rate; $\mathrm{CO}_{2}$ concentration; occupancy estimation; demand controlled ventilation (DCV); energy efficiency

\section{Introduction}

According to the current European Directives [1,2], many strategies have been developed to improve indoor air quality (IAQ) and thermal comfort of public buildings. Moreover, programs of energy efficiency for buildings to reduce their energy needs through either a functional design of new structures or a refurbishment of existing ones have been encouraged.

In this perspective, measures for energy efficiency improvement of heating, ventilation, and air cooling (HVAC) systems appears to be of relevant importance in order to achieve the objective of energy sustainability. The interest on such topic has recently been further exacerbated by the spreading of the well-known COVID-19 pandemic; a strict IAQ control is of relevant importance because it can prevent airborne virus transmission in occupied spaces.

As ventilation is fundamental for maintaining adequate indoor air quality (IAQ), including health and thermal comfort, among the various elements, the possibility of reducing energy needs associated with ventilation and air exchange rate is a topic of particular interest. The energy consumption for ventilation cannot be easily estimated. In the literature, several works report implementation of control strategies on specific case studies for the reduction of energy requirements but maintain quite high standards or thermal comfort and IAQ. Papers containing experimental analyses and methodologies considering both individual houses and public buildings are available.

Carbon dioxide can be considered a possible marker for a quite simple estimation of occupancy level of buildings such as schools and universities and consequently for estimating optimal ventilation rates. Belmonte et al. [3] provide a methodology to compare indoor air quality in residential buildings. 
The methodology is based on monitoring data of $\mathrm{CO}_{2}$ concentration, and the authors also estimate the air flow rate profile necessary to maintain a selected $\mathrm{CO}_{2}$ concentration in two different zones of the apartments.

Merema et al. [4] present monitoring campaigns in offices and school buildings, where IAQ is controlled through a demand controlled ventilation system. The system permits one to maintain good air quality, even in the presence of reduced air flow rates; furthermore, significant reductions of energy consumption are obtained.

In [5], the results of three different ventilation strategies for maintaining thermal comfort and good air quality level in Norwegian primary schools are presented. The authors compare a constant air volume ventilation system (in which the ventilation rate is constant and equal to the maximum value, depending on users) and two demand control ventilation strategies, where the choice of the air flow rate depends either on the $\mathrm{CO}_{2}$ concentration or the presence/absence of users in the room. In the paper, the strategy based on $\mathrm{CO}_{2}$ monitoring appears to be the most promising one, with energy savings of $62 \%$ with respect to constant air volume system. Similar results were found in [6], where the authors compare a constant air volume system and a demand control ventilation system based on $\mathrm{CO}_{2}$ measurements. Simanic et al. [7] present the outcomes of seven monitoring activities in primary schools in Sweden, where variable air volume systems are usually employed. The results show that a low $\mathrm{CO}_{2}$ concentration is achieved by the use of quite high values of ventilation rates (over $0.01 \div 0.02 \mathrm{~m}^{3} / \mathrm{s} \times$ occupant).

The reduction of energy consumption should not compromise the requirement for a correct IAQ level. A given amount of fresh air is required to determine comfortable indoor environments, maintaining recommended values of relative humidity and pollutants concentrations, which can hamper users' health and productivity. Several indicators can be linked to IAQ control, but one of the most used is the $\mathrm{CO}_{2}$ concentration.

In engineering applications, humans' exhalations of $\mathrm{CO}_{2}$ are often correlated to metabolic rate, and this is connected to the specific activity [8]. In medical and biological applications, the specific $\mathrm{CO}_{2}$ production rate is an object of a detailed study, even through experimental measurements [9]; the values of those exhalation rates differ from the estimates of engineering applications.

In an IAQ analysis through $\mathrm{CO}_{2}$ measurements, excessively high values of carbon dioxide in closed environments can be an indication of malfunctioning of mechanical ventilation systems and an excessive occupancy density, which can lead to undesired issues for users, such as headache and somnolence. Some studies have also reported a reduction of users' productivity in environments with higher $\mathrm{CO}_{2}$ concentration [10,11]; another work [12] highlights the concept that decrease in users' performance at school and work is probably due to concurrent effects of both high $\mathrm{CO}_{2}$ concentrations and other adverse conditions (e.g., bad thermal conditions, exposure to other pollutants).

Even if this latter aspect should be further studied, it is well established that a $\mathrm{CO}_{2}$ concentration over 1000-1500 ppm should be avoided $[13,14]$ to maintain good indoor air quality conditions. Strictly speaking, the objectives of maintaining good IAQ with reduced energy use for the operation of an HVAC system is difficult, because the second objective usually requires high ventilation rates, and this has a consequence in terms of increase of the energy necessary for air exchange and for air treatment. A compromise is not simple and would require detailed quantitative knowledge of the link between air quality parameters and operation of thermal and ventilation control systems in the specific building under analysis. This knowledge is not exactly evident from the analysis of the above mentioned references. The problem is particularly relevant for public buildings, where it is estimated that around a third of energy consumption related to thermal control is due to ventilation. In literature, in particular, it is found that the choice of correct ventilation rates is difficult, especially in educational buildings, as considered in two recent papers $[15,16]$.

This is due to the fact that air exchange rate is often managed automatically without considering the real occupation profile of the building and of the various rooms but using maximum values imposed by the technical standards with a quite high occupation of indoor spaces (e.g., $80 \%$ of the maximum 
occupation). Finding an optimal value of air exchange rate based on the maintenance of maximum levels of $\mathrm{CO}_{2}$ concentration in educational buildings is prescribed by various regulatory documents from EU levels down to national design guidelines for educational buildings, but the dynamic control of the air flow rate is not always considered.

Considering the aforementioned elements, in the present paper, the monitored data of $\mathrm{CO}_{2}$ concentration obtained during examinations and lessons in several classrooms within the Engineering School of the University of Pisa, previously presented in [17], are here used to provide a possible correlation between $\mathrm{CO}_{2}$ concentration increase and number of occupants. The experimental analysis was performed in various classrooms of university buildings. The rooms were characterized by different geometrical parameters, such as surface area, volume, and shape, and operating parameters, such as indoor occupation. Then, a multi-objective methodology was proposed to establish optimal profile of demanded controlled ventilation of indoor spaces based on the actual occupation's profile obtained by monitoring the increase of carbon dioxide concentration with time.

The multi-objective methodology was based on the possibility of obtaining a compromise between occupant's comfort and energy used for mechanical ventilation. The direct correlation of occupancy profile of the buildings permits one to obtain an adaptive solution based particularly on the simple measurement of $\mathrm{CO}_{2}$ in order to define a dynamic and demanded controlled ventilation (DCV) strategy that permits one to maintain the required standards of $\mathrm{CO}_{2}$ concentration with minimum energy use, thus pursuing the objective of energy saving while satisfying the occupants' comfort.

\section{The Connection of Carbon Dioxide Concentration, Occupation of the Indoor Spaces, and Air Ventilation Rate in Indoor Spaces}

The occupancy detection of buildings and indoor spaces in general is important both for maintaining adequate IAQ standards (in term of temperature, humidity, and concentration of specific pollutants such as $\mathrm{CO}_{2}$ ) and for energy efficiency purposes. Due to the relevant energy consumption connected to HVAC system operation, for maintaining temperature and humidity standards and pollutant concentration, a quite accurate estimation of the actual number of users inside a building or of a single room can be useful in order to modulate the operation of the HVAC system, varying the supply temperature to terminal units and an appropriate value of the air exchange rate.

In particular, supplying a fixed value of design volume exchange of fresh air in any condition of occupancy can lead to relevant energy consumption, particularly in spaces where the number of users varies frequently, as in educational buildings, in which different groups of students occupy the same classroom in different part of the day [18].

Among the various methods for the determination of occupants' number, the method using $\mathrm{CO}_{2}$ concentration and its rise appears to be a particularly interesting one. Furthermore, it also solves some of the major issues related to the adoption of the other methods, such as use of video-cameras [19].

The use of indoor $\mathrm{CO}_{2}$ concentration data for estimating the occupants' number could be less accurate than other technologies (such as video-cameras or counters) for defining the exact number of persons present inside the indoor space; regardless, it can be considered quite useful for an approximate quantitative estimation of a percentage value of occupation without interferences due to other devices or privacy concerns.

In this work, $\mathrm{CO}_{2}$ was considered as the only component to be monitored. This component, even if it is not considered a real indoor pollutant, is correlated to IAQ in several studies, and its generation is due to people breathing. As its monitoring is easier than other indoor pollutants (e.g., carbon monoxide, formaldehyde, volatile organic compounds VOCs) thanks to relatively "cheap" sensors, it can be monitored as a "pollutant" of an indoor environment, as reported in other studies in literature.

From a theoretical point of view, considering an indoor space, a mass balance for $\mathrm{CO}_{2}$ can be written, considering valid the following assumptions:

- $\quad$ uniform concentration in the room, assuming a well-mixed model; 
- constant value of outdoor $\mathrm{CO}_{2}$ concentration;

- well-defined value of the generation rate of the occupants;

Assuming the previous hypotheses, the $\mathrm{CO}_{2}$ indoor concentration rise can be assumed to be dependent on air ventilation rate, imposed with a mechanical device or dependent on infiltration losses through doors and windows frames, with the following equation:

$$
\mathrm{V} \frac{\mathrm{dC}_{\left\{\mathrm{CO}_{2\}}\right\}}(\mathrm{t})}{\mathrm{dt}}=\dot{r} \mathrm{n}_{\mathrm{occ}}-\dot{\mathrm{m}}\left(\mathrm{C}_{\left\{\mathrm{CO}_{2}\right\}}(\mathrm{t})-\mathrm{C}_{\mathrm{ext}}\right)
$$

where $\mathrm{C}_{\left\{\mathrm{CO}_{2}\right\}}$ is the indoor concentration of carbon dioxide, $\mathrm{V}$ the total volume of the room, $\mathrm{n}_{\mathrm{occ}}$ the number of occupants, $\dot{r}$ the $\mathrm{CO}_{2}$ generation rate per person, $\dot{\mathrm{m}}$ the air flow rate due to ventilation (mechanical of natural due to infiltration) expressed in $\mathrm{m}^{3} / \mathrm{s}$, and $\mathrm{C}_{\text {ext }}$ is the outdoor $\mathrm{CO}_{2}$ concentration. $\mathrm{CO}_{2}$ concentration variation in the room can also be written in explicit form, thus, at time $t$, it is equal at:

$$
\mathrm{C}_{\left\{\mathrm{CO}_{2}\right\}}(\mathrm{t})=\mathrm{C}_{\left\{\mathrm{CO}_{2}\right\}}(\mathrm{t}=0) \exp \left(-\frac{\dot{\mathrm{m}}}{\mathrm{V}} \mathrm{t}\right)+\left(\mathrm{C}_{\text {ext }}+\frac{\dot{r} \mathrm{n}_{\text {occ }}}{\dot{\mathrm{m}}}\right)\left(1-\exp \left(-\frac{\dot{\mathrm{m}}}{\mathrm{V}} \mathrm{t}\right)\right)
$$

The two equations are simple mass balance for $\mathrm{CO}_{2}$ concentration inside a definite volume. However, these formulas are reported in the literature, such as [15].

Considering Equation (2), it is easy to understand how the variation of $\mathrm{CO}_{2}$ concentration can be easily connected to the number of occupants if the rate of generation and the air exchange rate are exactly known, while the use of such a kind of model is quite difficult if no control on ventilation rate is available.

In a recent paper [17], the correlation between the variation of $\mathrm{CO}_{2}$ concentration and the occupancy profile of the room was analyzed, proposing a linear correlation between the $\mathrm{CO}_{2}$ concentration rise and the specific volume per occupant. It was discussed how, for a specific activity and for a specific category of users (students and young people), the most relevant variables are the volume available for each person, the specific production, and the air exchange rate.

The correlation was also verified with other variables, considering room characteristics and occupation data as particularly relevant.

Equation (1) can be also reformulated in the case of "closed volume" neglecting infiltration and natural ventilation effects and in absence of mechanical ventilation, thus considering the production rate as the predominant factor for $\mathrm{CO}_{2}$ concentration variation inside the room:

$$
\frac{\mathrm{V}}{\mathrm{n}_{\mathrm{occ}}}=\dot{r} \frac{1}{\frac{\left.\mathrm{dC}_{\left\{\mathrm{CO}_{2}\right\}} \mathrm{t}\right)}{\mathrm{dt}}}
$$

Neglecting infiltration appears to be especially accurate in new or renovated buildings, where doors and windows are airtight. Using an accurate value of the production rate $\dot{r}$, knowing the volume of the room and the $\mathrm{CO}_{2}$ concentration variation in a given time period, Equation (3) allows for the estimation of the number of occupants in the room, and the estimation of the $\mathrm{CO}_{2}$ production rate per person is an essential element. Furthermore, one can observe a hyperbolic correlation between the $\mathrm{CO}_{2}$ concentration rise and the specific volume per occupant.

The generation rate depends on different elements—such as age, weight, and type of activity—and typical values of exhalation per person for common metabolic activities found in literature should be used if validated through experimental results. Then, one can use Equation (1) to estimate the mechanical ventilation air flow rate to be injected in the room to maintain an optimal operating temperature as well as a value of $\mathrm{CO}_{2}$; this air flow rate can be adjusted to reduce energy requirements, thus obtaining an advantageous value for both the objectives.

Figure 1 provides a correlation between the derivative of $\mathrm{CO}_{2}$ concentration and the air volume per occupant based on the application of the model previously exposed in Equation (3) for three 
different values of $\mathrm{CO}_{2}$ production rate: (i) $0.2 \mathrm{~L} / \mathrm{min}$, used as a typical lower value for people sitting or involved in light intensity activities, such as students during teaching lessons ( $\left.\dot{r}_{1}\right)$; (ii) $0.8 \mathrm{~L} / \mathrm{min}$, used for people standing and operating a medium physical activity $\left(\dot{r}_{2}\right)$; and (iii) $1.5 \mathrm{~L} / \mathrm{min}$, used for high intensity physical activities $\left(\dot{r}_{3}\right)$. The validity of Equations (2) and (3) was tested using the results of a detailed experimental analysis in several classrooms of educational buildings with different shapes and occupation profiles [17].

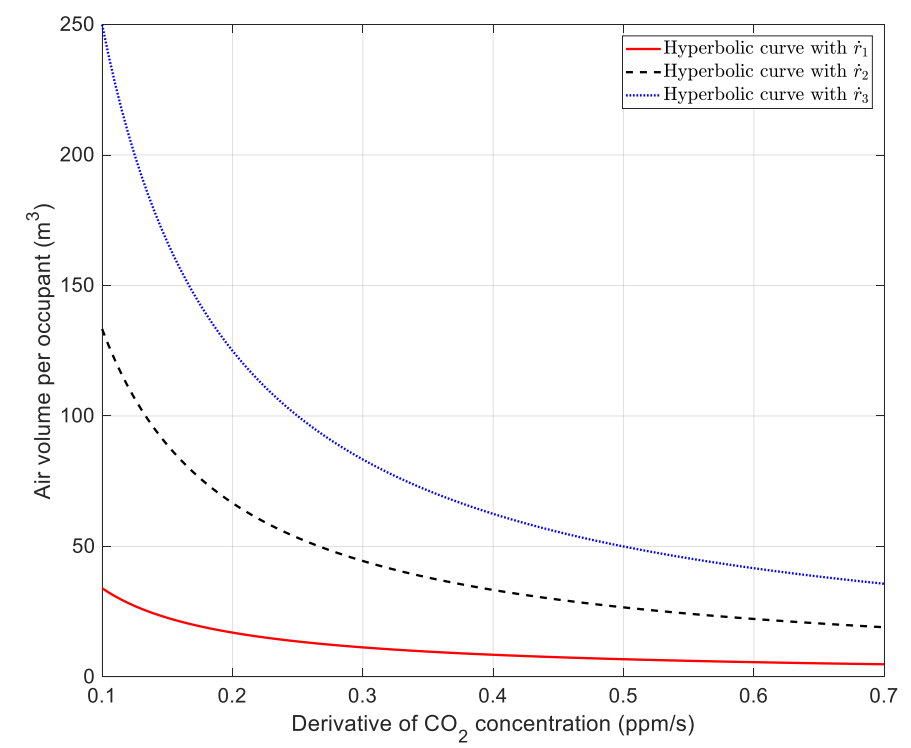

Figure 1. Correlation between derivative of $\mathrm{CO}_{2}$ concentration and air volume per occupants for different values of $\mathrm{CO}_{2}$ production rate per occupant.

\section{Air Exchange Rate and Direct Correlation with Real Occupation: Data from a Monitoring Activity}

In order to maintain the required condition of comfort concerning temperature, humidity, and $\mathrm{CO}_{2}$ concentration, this last value being a typical pollutant marker in indoor spaces, the operation of HVAC in order to control the environmental parameters has to be correlated with the real occupation of the spaces. In particular, air exchange rate in closed rooms and indoor spaces generally causes relevant additional energy consumption. This is because the air that is circulated from the external environment, usually at lower (in winter) or higher (in summer) temperatures than the environment depending on the season, must be brought to the room temperature. The energy consumption is higher the greater the flow rate of air to exchange (air flow rate volume) and the difference in temperature between the external environment and the room are. The higher the required air exchange rate is, the better the air quality in the indoor space will be, but the ventilation power required and the overall energy consumption will also be higher.

In air conditioning systems, the air exchange can be total or partial. In the latter case, a percentage of the air taken from the room could be recirculated, and only a fraction of the same would be fresh air. After the COVID 19 health emergency, the legislation of many countries has imposed that, in newly designed systems and in public buildings in general, the percentage of air recovered from the external environment should be $100 \%$ and no recirculation of air from the room could be possible. This will certainly lead to greater energy consumption for the operation of the HVAC system and particularly of the ventilation rate. The energy consumption for the operation of an HVAC system is linked both to the transmission losses, proportional to the temperature difference between the room and the external environment, and to the thermal conductance of the structure (UA) and the mass transfer, connected to a percentage of volume of the room $(\mathrm{V})$ that must be renewed in the unit time (usually one hour).

Under normal conditions (air exchange rate in the range $0.3-1 \mathrm{Vol} / \mathrm{h}$ ), the energy consumption in connection with air ventilation rate can be estimated to be between $20 \%$ and $40 \%$ of the total energy 
consumption. However, if a more relevant air exchange rate is necessary, it would be possible that the energy consumption could be dependent on the air exchange rate, which could be higher than those connected to the heat transfer.

Usually, the fraction of the volume of the room that needs to be exchanged is established by technical regulations. This establishes a rather high value connected to a maximum use of the room, but no specific correlation with the real number of occupants is used. However, the fraction of air that must be renewed is certainly a function of the real occupation of the room. In the future, when there is reduction of social interaction and the rooms are less crowded than in the past, it will be very important to correlate the air mass exchange rate to the real number of occupants.

As previously mentioned, in this work, the results of a monitoring campaign in several classrooms within the Engineering School of the University of Pisa were used for defining an optimal value of the of the air exchange rate.

The main characteristics of the monitored classrooms in terms of volume, floor surface, and effective number of occupants during the various experiments are reported in Table 1 . The monitoring campaign in each classroom lasted for a certain number of minutes, depending on the length of the exam or the lecture ongoing during the measurement. All the details of the experimental analysis are provided in [17]. The experimental analysis was carried on without action of mechanical ventilation and the air exchange rate. Thus, the air exchange rate was only possible due to infiltrations from window frames and doors.

Table 1. The main data of the 12 monitored classrooms.

\begin{tabular}{|c|c|c|c|c|c|c|c|}
\hline Classroom & Building & Level & $\begin{array}{l}\text { Max. } \\
\text { Occupancy } \\
\text { (N) }\end{array}$ & $\begin{array}{c}\text { Floor } \\
\text { Surface, } S \\
\left(\mathrm{~m}^{2}\right)\end{array}$ & $\begin{array}{c}\text { Volume V } \\
\left(\mathrm{m}^{3}\right)\end{array}$ & $\begin{array}{c}\text { Ratio V/S } \\
\left(\mathrm{m}^{3} / \mathrm{m}^{2}\right)\end{array}$ & $\begin{array}{l}\text { Vol. for Student } \\
\text { at Full } \\
\text { Occupation }\left(\mathrm{m}^{3}\right)\end{array}$ \\
\hline 0 & LAB & $1 \mathrm{st}$ & 20 & 20 & 58 & 2.90 & 2.90 \\
\hline 1 & $\mathrm{~A}$ & $1 \mathrm{st}$ & 108 & 88 & 482 & 5.48 & 4.46 \\
\hline CL1 & B & $1 \mathrm{st}$ & 116 & 216 & 583 & 2.70 & 5.03 \\
\hline 2 & B & 1st, 2nd & 366 & 336 & 1426 & 4.24 & 3.90 \\
\hline 3 & C & 4th & 72 & 73 & 212 & 2.90 & 2.94 \\
\hline 4 & $\mathrm{~F}$ & $1 \mathrm{st}$ & 309 & 286 & 1587 & 5.55 & 5.14 \\
\hline 5 & $\mathrm{~F}$ & $1 \mathrm{st}$ & 208 & 216 & 1220 & 5.65 & 5.87 \\
\hline 6 & $\mathrm{~F}$ & $1 \mathrm{st}$ & 109 & 130 & 721 & 5.55 & 6.61 \\
\hline 7 & $\mathrm{~F}$ & $1 \mathrm{st}$ & 196 & 197 & 1094 & 5.55 & 5.58 \\
\hline 8 & $\mathrm{~F}$ & $1 \mathrm{st}$ & 104 & 129 & 717 & 5.56 & 6.89 \\
\hline 9 & $\mathrm{~F}$ & $1 \mathrm{st}$ & 109 & 128 & 711 & 5.55 & 6.52 \\
\hline 10 & $\mathrm{~F}$ & $1 \mathrm{st}$ & 140 & 131 & 439 & 3.35 & 3.14 \\
\hline
\end{tabular}

One of the classrooms that particularly identified with label 0 was used as the benchmark room for experimentally defining typical values of $\mathrm{CO}_{2}$ production rates for each student. The measurements of $\mathrm{CO}_{2}$ concentration together with the measurements of indoor temperature and relative humidity were obtained using up to four different sensors, Chauvin Arnoux C.A 1510, [20]. Concerning the specific problem of $\mathrm{CO}_{2}$ concentration measurement, the sensors permitted us to cover a measurement range 0-5000 ppm with an uncertainty of $\pm 3 \%$ of the reading $\pm 50 \mathrm{ppm}$ at $25^{\circ} \mathrm{C}$ at atmospheric pressure. Even in literature, $\mathrm{CO}_{2}$ measurements are usually carried out through a single sensor placed next to the center of the room, and the uniformity of carbon dioxide concentration in the room must be proven. Thus, in some of the experiences, two or three sensors were placed in different zones of the room at breathing level to check if the assumption of well-mixed indoor volume could be realistic.

Two typical examples of $\mathrm{CO}_{2}$ variation (increase) with time are shown in Figures 2 and 3. In Figure 2, the profile is related to an experimental analysis of room 5, where two sensors were used to measure the $\mathrm{CO}_{2}$ concentration increase. Figure 3 provides the $\mathrm{CO}_{2}$ concentration profile within the classroom identified as CL1 (computer lab). 


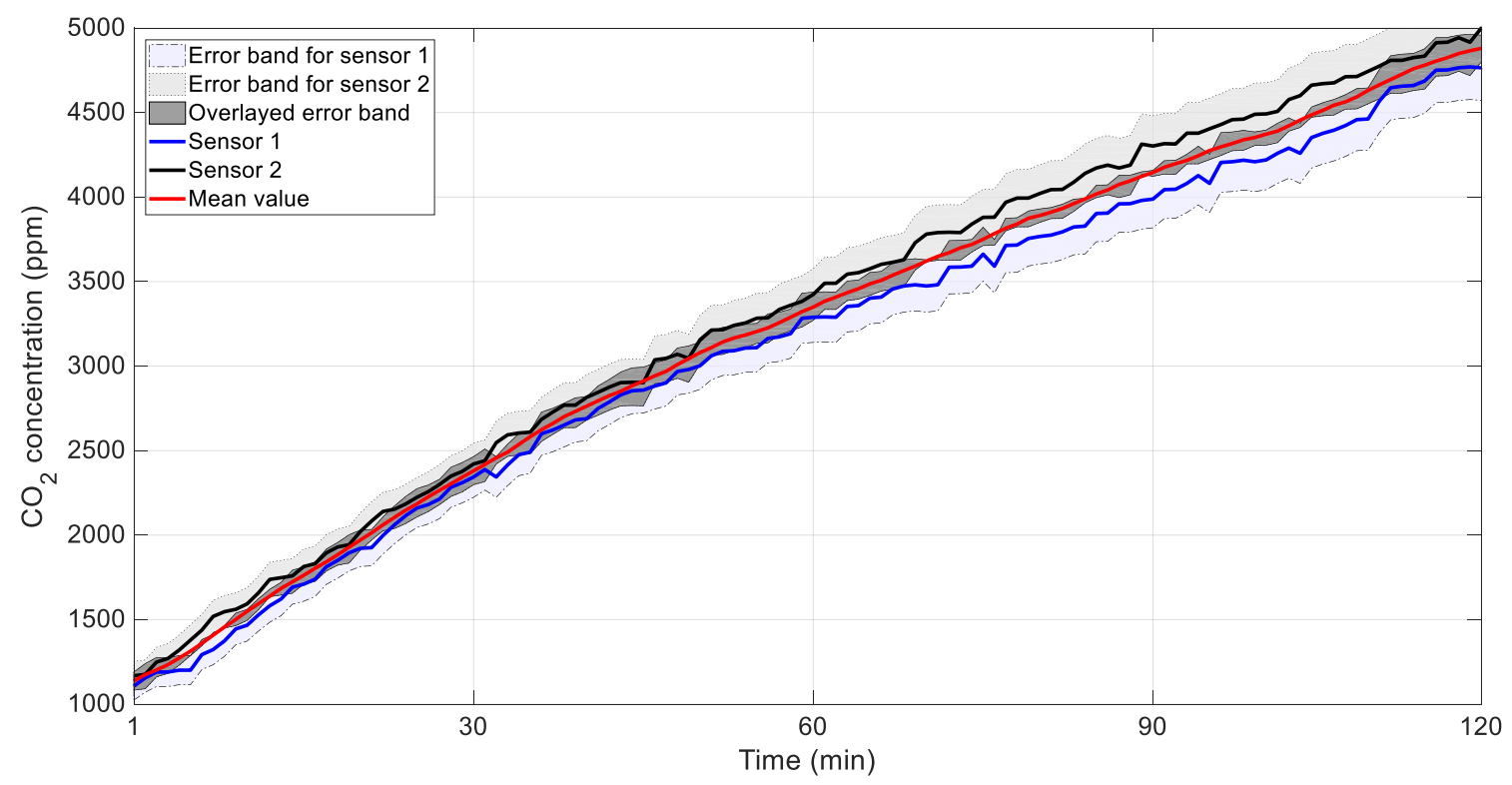

Figure 2. $\mathrm{CO}_{2}$ concentration profiles in a particular experience in classroom 5 .

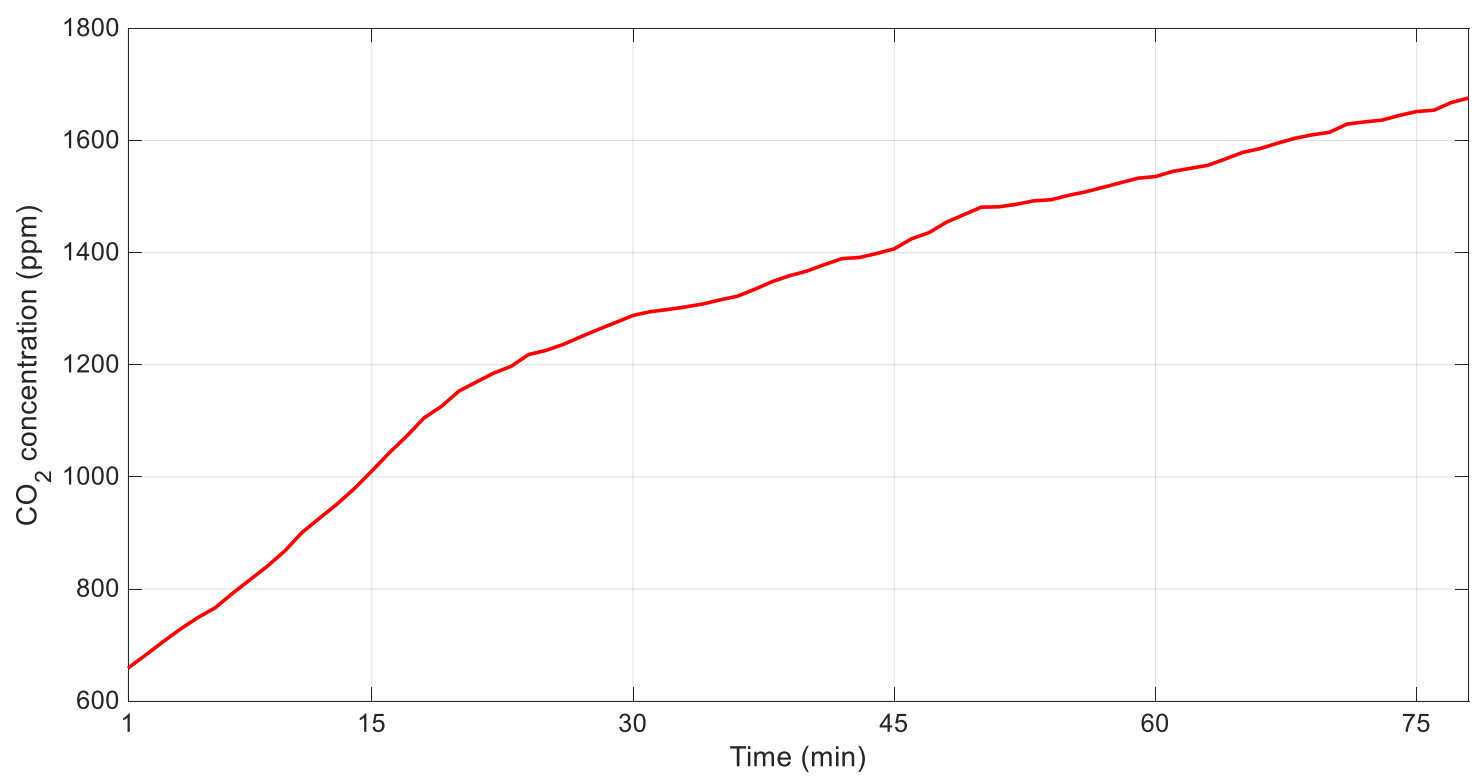

Figure 3. $\mathrm{CO}_{2}$ concentration profiles in the computer lab (CL1) during typical didactic activity.

In all the cases where two or more sensor were used, similar profiles for the $\mathrm{CO}_{2}$ measurements were found, similar to those provided in the previous Figure 2. Possible differences among the measurement of the sensors were within the error band of the sensors represented by the filled area, thus the hypothesis of well-mixed room was considered valid.

Table 2 provides the results obtained in all the critical cases when the threshold value of $1500 \mathrm{ppm}$ for $\mathrm{CO}_{2}$ was overcome. Results show the starting value and an average value of the $\mathrm{CO}_{2}$ concentration increased in each classroom, which was evaluated in the first 10-15 min of monitoring, and an evaluation of the elapsed time between the start of the measurement and the time in with the $\mathrm{CO}_{2}$ threshold value $(1500 \mathrm{ppm})$ was reached. This time duration was used to evaluate the $\mathrm{CO}_{2}$ concentration increase with time. Only in two cases was the threshold limit lower than the initial value, meaning that, during the previous didactic activity, the $\mathrm{CO}_{2}$ concentration increased over the limit, and natural ventilation was not sufficient to have the concentration decreased; in those two cases, the estimation of the $\mathrm{CO}_{2}$ concentration increase with time was done using the concentration at the starting value of the lesson. 
Table 2. $\mathrm{CO}_{2}$ concentration at the beginning and at the end of the monitoring experience.

\begin{tabular}{|c|c|c|c|c|c|c|}
\hline $\begin{array}{c}\text { Experiment } \\
\text { Identification } \\
\text { (Room/Number) }\end{array}$ & $\begin{array}{l}\text { Number of } \\
\text { Students }\end{array}$ & $\mathrm{V} / \mathrm{n}_{\mathrm{occ}}\left(\mathrm{m}^{3}\right)$ & $\begin{array}{c}\mathrm{CO}_{2} \\
\text { Concentration } \\
\text { at } \mathrm{t}=0(\mathrm{ppm})\end{array}$ & $\begin{array}{l}\text { Maximum } \\
\mathrm{CO}_{2} \\
\text { Concentration } \\
\text { Measured }\end{array}$ & $\begin{array}{c}\mathrm{CO}_{2} \\
\text { Concentration } \\
\text { Increase with } \mathrm{t} \\
(\mathrm{ppm} / \mathrm{s})\end{array}$ & $\begin{array}{c}\text { Time for } \\
\text { Overcoming } \mathrm{CO}_{2} \\
\text { Threshold } \\
(1500 \mathrm{ppm})(\mathrm{min})\end{array}$ \\
\hline 0 & 20 & 2.90 & 704 & 1841 & 0.28 & 20 \\
\hline 1 & 68 & 7.08 & 782 & 2566 & 0.17 & 72 \\
\hline CL1 & 38 & 15.08 & 659 & 1676 & 0.22 & 55 \\
\hline 3 & 72 & 2.94 & 1264 & 2960 & 0.59 & 6 \\
\hline $4 \# 1$ & 58 & 27.36 & 678 & 1741 & 0.14 & 95 \\
\hline $4 \# 3$ & 93 & 17.06 & 596 & 2685 & 0.18 & 78 \\
\hline $5 \# 1$ & 168 & 7.30 & 1138 & 4913 & 0.52 & 10 \\
\hline $5 \# 3$ & 106 & 11.50 & 1100 & 3409 & 0.26 & 21 \\
\hline $7 \# 1$ & 146 & 7.49 & 791 & 3297 & 0.40 & 24 \\
\hline 8 & 54 & 13.27 & 1257 & 2383 & 0.37 & 8 \\
\hline 9\#1 & 54 & 13,16 & 1512 & 2334 & 0.43 & 0 \\
\hline 9\#2 & 59 & 12.05 & 1648 & 3369 & 0.26 & 0 \\
\hline $10 \# 2$ & 50 & 8.78 & 695 & 2410 & 0.42 & 27 \\
\hline
\end{tabular}

Even if all the mentioned variables seemed to be meaningful, the experimental results obtained in the particular conditions demonstrate that a hierarchical distribution of the variables could be identified; the most relevant one seemed to be, as expected, the volume available for each student.

The values of the rise of $\mathrm{CO}_{2}$ concentration, expressed by the derivative $\frac{\mathrm{dC}_{\left\{\mathrm{CO}_{2}\right\}}}{\mathrm{dt}}$ estimated in the experimental analysis referred in [17], ranged between $0.1 \mathrm{ppm} / \mathrm{s}$ up to $0.7 \mathrm{ppm} / \mathrm{s}$, with maximum occurrence in the range between 0.2 and $0.5 \mathrm{ppm} / \mathrm{s}$.

In order to establish a quantitative correlation between the number of persons inside a room and the evolution of $\mathrm{CO}_{2}$ concentration with time, according to the model provided in Equations (1)-(3), accurate knowledge of the value of the $\mathrm{CO}_{2}$ production rate per occupant was needed. This value can be obtained with reference to the available literature and technical standards, but it can also be measured. In the present paper, this second path was considered. In particular, the benchmark room was the one identified with label 0 in Table 1.

$\mathrm{CO}_{2}$ was measured in two different point during the first phase of a short duration examination (a test of $30 \mathrm{~min}$ ). A total number of 20 students were present inside the room at the initial time of the experimental analysis, and the windows were closed. The two sensors measured an almost uniform profile of $\mathrm{CO}_{2}$ increase; the mean values are shown in Figure 4. In the first phase (five minutes), the sensors began to measure; $\mathrm{CO}_{2}$ was almost constant as the classroom was unoccupied. Then, in a few minutes, twenty students entered and sat inside the room for about $30 \mathrm{~min}$. Then, the door was opened, and the majority of the students left the room (phase 3), while only five of them remained inside.

Considering the experimental results obtained during this short time experimental analysis, using Equation (2), a mean value of $\mathrm{CO}_{2}$ production rate equal to $0.201 / \mathrm{min}$ per person could be estimated. The value obtained agreed quite well with the specific activity when compared with $\mathrm{CO}_{2}$ production rates available in the literature $[8,9,21,22]$.

With reference to the available literature, represented by the four papers above, the values of this production rate in general cases can range between a minimum value of $0.21 / \mathrm{min}$ up to a maximum value of $0.45 \mathrm{l} / \mathrm{min}$. In general, on technical engineering standards for a sedentary activity, a level of about $18 \mathrm{l} / \mathrm{h}$ that equals $0.3 \mathrm{l} / \mathrm{min}$ per adult person can be estimated. The values obtained considering the results of the experimental analysis during typical teaching activity were lower than those suggested by technical standards (e.g., [23]), but they were in accordance with some estimates evaluated by medical standards [21] and other monitoring campaigns [22]. 


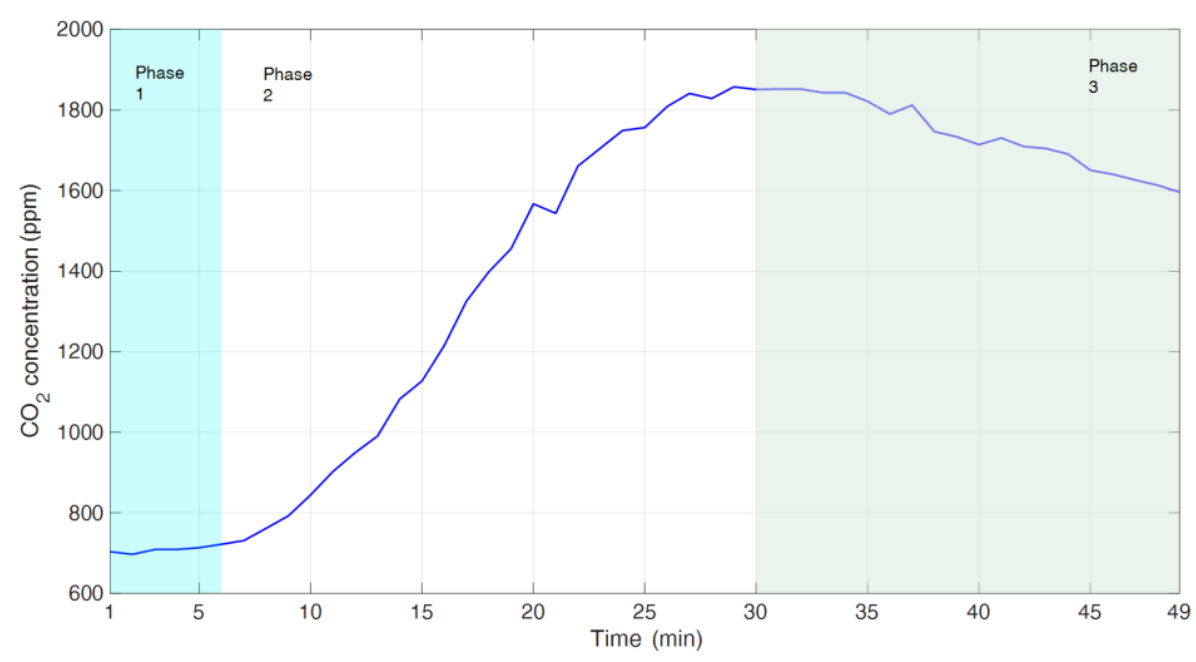

Figure 4. Evolution of $\mathrm{CO}_{2}$ concentration in the room 0 for defining the $\mathrm{CO}_{2}$ production rate.

\section{Correlation of $\mathrm{CO}_{2}$ Concentration Rise and Occupation for Defining Optimal Air Exchange Rate}

As already discussed in the introduction, the idea of predicting the occupancy using physical and statistical $\mathrm{CO}_{2}$ measurements has been diffusely expressed in the literature and has been object of recent analyses as well $[24,25]$. On the other hand, a demand controlled ventilation (DCV) strategy within the context of the American Society of Heating Refrigerating and Air-Conditioning Engineers (ASHRAE) Technical Standards is developed in [26] for public buildings using a digital control system.

In the present section, the methodology defined was used to define a correct air exchange rate for indoor volume with the objective of controlling the rise of $\mathrm{CO}_{2}$ concentration. The analysis refers to some of the situations previously tested. The idea of defining a procedure for calculating a value of the air exchange rate, a demand controlled mechanical ventilation rate, has already been developed in the literature, and papers about this specific topic are already available $[27,28]$.

A first outcome of the analysis was the validation of the correlation between the $\mathrm{CO}_{2}$ increase and the specific volume per student in Equation (2) using the results of the specific experimental analysis. The problem in using Equation (3) is that it neglects air change in the room. Some of the results are shown in Figure 4, where the twelve pair of values $\left(\frac{\Delta \mathrm{C}_{\left\{\mathrm{CO}_{2}\right\}}}{\Delta \mathrm{t}}, \frac{\mathrm{V}}{\mathrm{n}_{\mathrm{occ}}}\right)$ obtained considering the data acquired in twelve specific experimental analyses are reported. Figure 5 also shows a hyperbolic curve, in red, representing the least-squares fitting curve for Equation (3). The value of $\mathrm{CO}_{2}$ production rate per person as evaluated using the least-squares fit, $\dot{r}_{l s}$, was $0.201 / \mathrm{min}$ and was equal to the estimated value derived after the monitoring of room 0 , defined as $\dot{r}_{0}$.

In particular, for classroom 5, a hyperbolic curve using the average value of $\mathrm{CO}_{2}$ production among the monitored classrooms, $\dot{r}_{\mathrm{m}}=0.22 \mathrm{l} / \mathrm{min}$, fit exactly the experimental results obtained in the experimental analysis $5 \# 1$. The curve is represented in Figure 5 with a black dotted line.

Some of the monitoring campaign results slightly deviated from the hyperbole due to the quite high infiltration rate (classroom 3, which is hosted in an old building). Moreover, a hyperbolic correlation between the rate of increase of $\mathrm{CO}_{2}$ concentration, $\frac{\Delta \mathrm{C}_{\left\{\mathrm{CO}_{2}\right\}}}{\Delta \mathrm{t}}$, and the volume available for each student, $\frac{\mathrm{V}}{\mathrm{n}_{\text {occ }}}$, seemed to fit the results of the experimental analysis quite well. A hyperbolic function was used with model $y=a / x$, with " $x$ " representing the derivative of $\mathrm{CO}_{2}$ concentration (in $\mathrm{ppm} / \mathrm{s}$ ) and " $\mathrm{y}$ " the air volume per student (in $\mathrm{m} 3$ ). The fitting procedure provided the "a" value, generally in the range between three and four (average value equal to 3.33). 


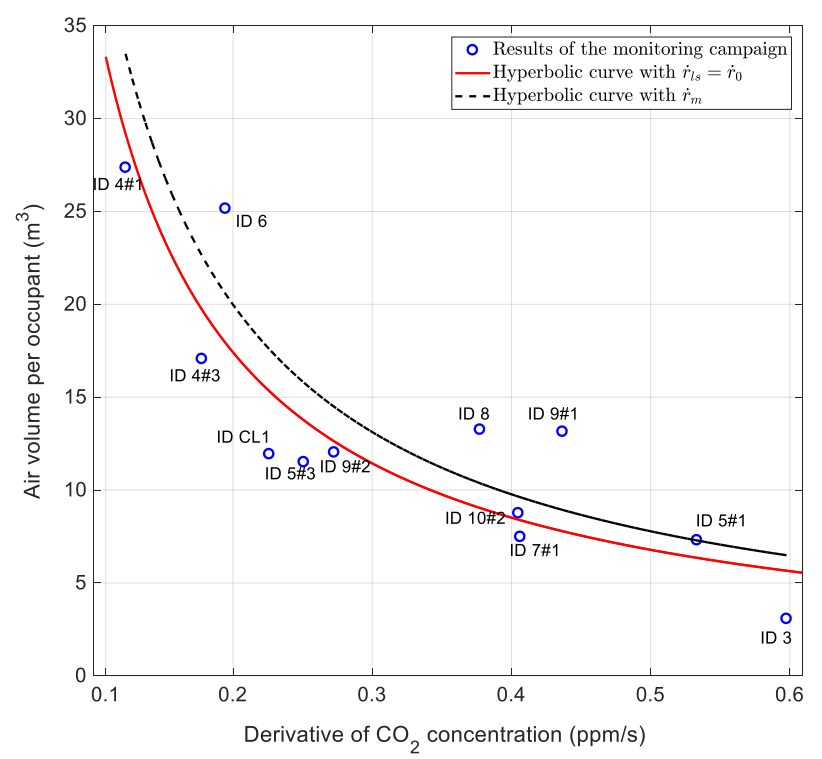

Figure 5. Correlation between $\mathrm{CO}_{2}$ concentration and air volume per student, obtained in the different experiments provided in [17].

Thus, by evaluating the variation of $\mathrm{CO}_{2}$ concentration in the room in a given time step (e.g., 10-15 $\mathrm{min}$ ) in the absence of mechanical ventilation and knowing the volume of the room, it was possible to estimate, with quite good accuracy, the approximate number of occupants. This procedure can be repeated periodically for controlling the operation of the mechanical ventilation system in order to meet the desired target in terms of temperature relative humidity and IAQ.

Therefore, it is possible to seek the mechanical air flow rate necessary to maintain a suitable value of $\mathrm{CO}_{2}$ concentration inside the room, $\dot{\mathrm{m}}$, using Equation (2).

As an example, the case identified with the label ID 5\#1 (classroom identified with label 5 and experience \#1) is considered. The case was used as a reference because, according to the results of Table 2, it is considered as a representative one. In this case, the classroom had a volume of $1220 \mathrm{~m}^{3}$, and several scenarios were assumed with different numbers of persons inside. An indoor steady-state $\mathrm{CO}_{2}$ concentration between $800 \mathrm{ppm}$ and $1500 \mathrm{ppm}$ was considered acceptable for maintaining good IAQ conditions. Thus, for each threshold value, it was possible to estimate the air flow rate values that allowed for maintenance of the $\mathrm{CO}_{2}$ concentration below the imposed value. The result of the application of the methodology is shown in Figure 6, where the thin colored curves represent the lines of equal air flow rate (iso $-\dot{m}$ ). For example, for a number of occupants equal to 122 (corresponding to a reference value of the volume available for each occupant of $10 \mathrm{~m}^{3}$ ) and a maximum allowable $\mathrm{CO}_{2}$ concentration of $1000 \mathrm{ppm}$, an air exchange rate of $0.8 \mathrm{~m}^{3} / \mathrm{s}$ was required.

The air exchange rate necessary for maintaining the desired $\mathrm{CO}_{2}$ concentration can also be correlated with the energy requirements. This value depends on the mass flow rate and on indoor and external temperature; through the following equation (referred to an operating time, $t$ ), the energy amount required for ventilation can be calculated:

$$
\mathrm{Q}_{\mathrm{v}}=\rho \dot{\mathrm{m}} \mathrm{c}_{\mathrm{p}}\left(\mathrm{T}_{\mathrm{int}}-\mathrm{T}_{\mathrm{ext}}\right) \mathrm{t}
$$

where $\dot{\mathrm{m}}$ is the air exchange rate, expessed in $\mathrm{m}^{3} / \mathrm{s}$. For users' comfort purposes, the indoor air temperature is limited within a given range (e.g., in winter, $18-22{ }^{\circ} \mathrm{C}$ and $24-27^{\circ} \mathrm{C}$ in summer). Thus, it is possible to display ventilation loads such as in Figure 6, where a combination of curves are shown varying ventilation rate as well as external and indoor temperature. In the figure, the markers represent ventilation loads at the same indoor temperature (i.e., rhomboidal, plus, round, square, and triangular markers refer to five different values of the indoor temperature, $T_{\text {in }}=18-22^{\circ} \mathrm{C}$ ), while the colorbar on the right side represents the energy consumption for ventilation, expressed in $\mathrm{kWh}$. 


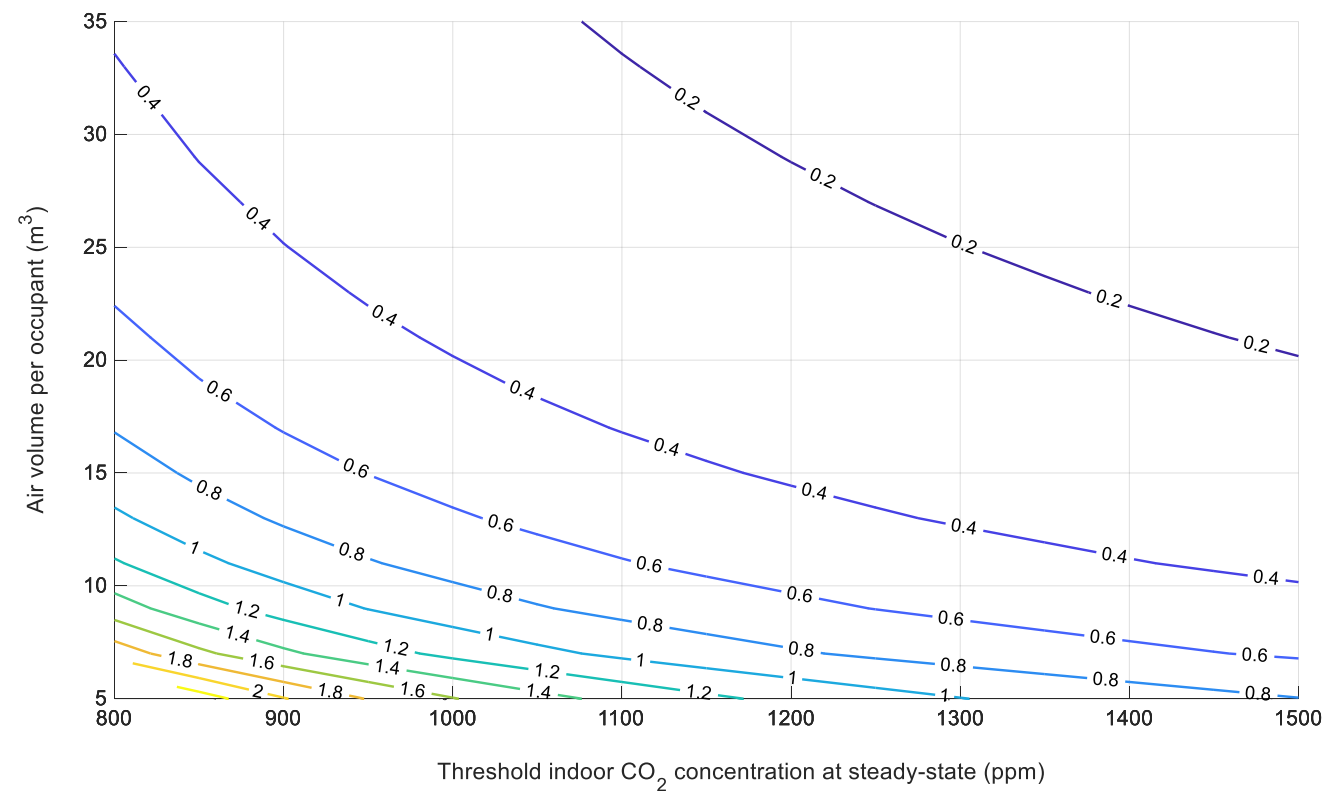

Figure 6. Air flow rates depending on desired $\mathrm{CO}_{2}$ concentration and air volume per occupant.

Referring to the air exchange rate $\dot{\mathrm{m}}=0.8 \mathrm{~m}^{3} / \mathrm{s}$, considering an external temperature of $0{ }^{\circ} \mathrm{C}$ and an indoor set-point temperature of $20^{\circ} \mathrm{C}$, a "ventilation load" of about $20 \mathrm{kWh}$ was required for each hour of operation in this specific classroom. In Figure 7, referring to the same case of classroom 5 , it is possible to select a different value of the air exchange rate (e.g., $\dot{\mathrm{m}}=0.6 \mathrm{~m}^{3} / \mathrm{s}$ referred to a threshold $\mathrm{CO}_{2}$ concentration, for example, $1200 \mathrm{ppm}$ ). In general, Figure $7 \mathrm{can}$ be used to evaluate, for each couple of $T_{\text {in }}$ and $T_{\text {ext }}$, the energy required for ventilation, (e.g., for a $T_{\text {int }}=20{ }^{\circ} \mathrm{C}$ and $\mathrm{T}_{\text {ext }}=0{ }^{\circ} \mathrm{C}, \mathrm{Q}_{\mathrm{v}}=15 \mathrm{kWh}$ ). If the air exchange rate necessary is at levels of $0.2 \mathrm{~m}^{3} / \mathrm{s}$, the energy used is reduced at $5-6 \mathrm{kWh}$.

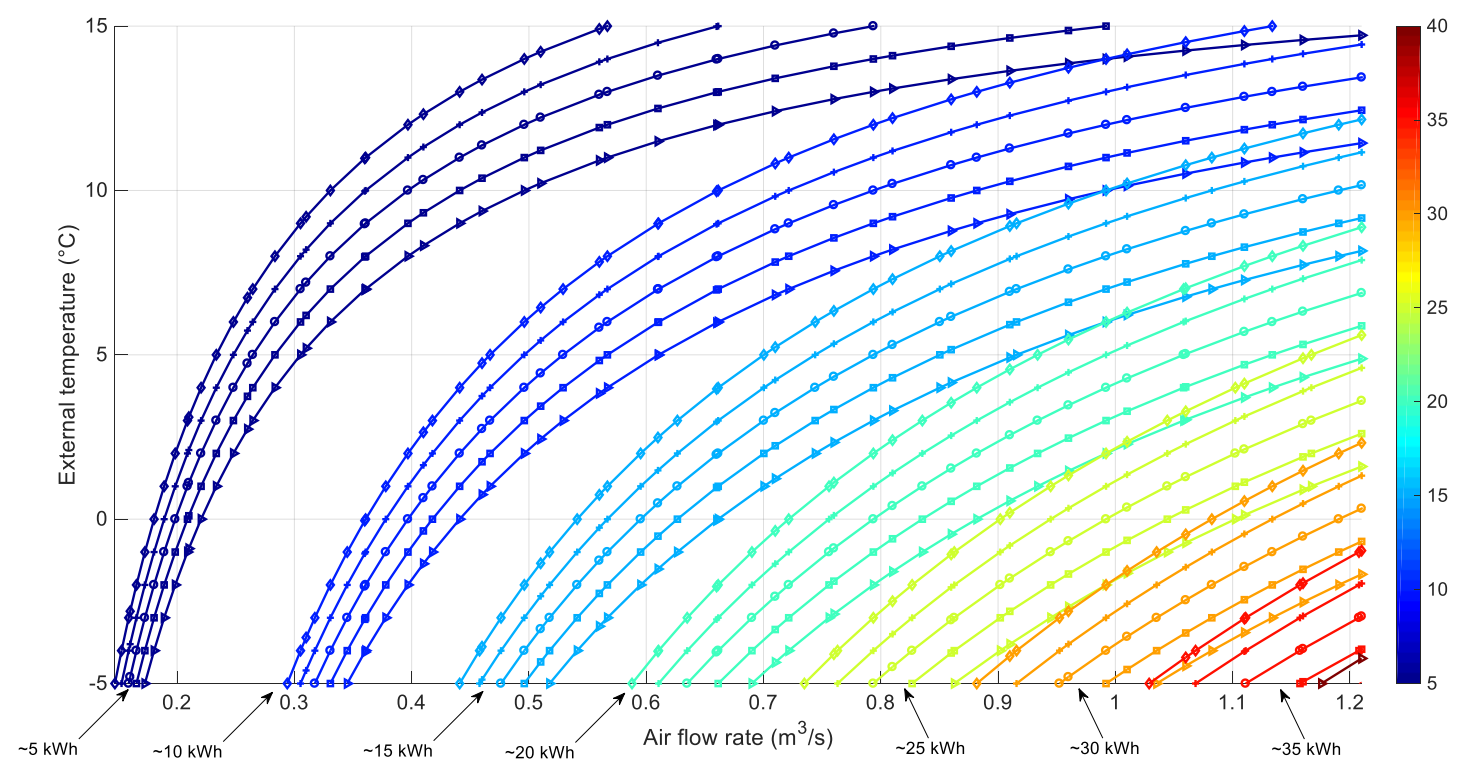

Figure 7. Energy consumption at different air exchange rates as well as external and indoor temperatures (classroom 5).

The definition of the air exchange rate imposed by a control on the upper value of $\mathrm{CO}_{2}$ concentration obtained using the proposed methodology can be used as a dynamic method for ventilation rate control as an alternative to actual regulation solutions, as proposed in the European Union EN 16798 [23]. 
This technical standard proposes a ventilation rate to dilute bio effluents from the occupants and a ventilation rate to remove pollution produced inside the building. The former term depends on the occupancy, while the latter term depends on the type of building. In particular, the parameters are the maximum number of the persons in the room and consequently the ventilation rate for occupancy per person, expressed in $1 /\left(\right.$ s person), and the floor area, $\mathrm{m}^{2}$, corresponding to the ventilation rate for emissions from building, $\mathrm{l} /\left(\mathrm{s} \cdot \mathrm{m}^{2}\right)$.

$$
\dot{\mathrm{m}}=\mathrm{n} \cdot \mathrm{q}+\mathrm{A}_{\text {floor }} \cdot \mathrm{q}_{\mathrm{b}}
$$

where $\mathrm{n}$ is the number of occupants, $\mathrm{q}$ is the ventilation rate for occupancy per person (expressed in $\mathrm{l} / \mathrm{s}$ person), $\mathrm{A}_{\text {floor }}$ is the surface of the room, and $\mathrm{q}_{\mathrm{b}}$ is the ventilation rate for emissions from building, expressed in $1 /\left(\mathrm{s} \cdot \mathrm{m}^{2}\right)$. In the technical standards, four categories are presented depending on the level of required IAQ. Here, two methods were considered, conventionally labeled with TS1 and TS2 (Technical Standards 1 and 2), corresponding with the maximum and the minimum values contained in Technical Standard EN 16798 [21] for comparison with the method proposed based on an accurate estimation of the occupation. In particular, the values of q ranged from $2.5 \mathrm{l} / \mathrm{s}$ person (category IV) to $10 \mathrm{l} / \mathrm{s}$ (category $\mathrm{I})$, while the values of $\mathrm{q}_{\mathrm{b}}$ ranged from $0.3 \mathrm{l} /\left(\mathrm{s} \mathrm{m}^{2}\right)$ for category I up to $1.0 \mathrm{l} /\left(\mathrm{s} \mathrm{m}^{2}\right)$ in case of category $\mathrm{I}$.

Method TS1. The air exchange rate is calculated depending on the maximum number of occupants for the specific classroom under analysis, $n_{\text {occ, } \max }$, and on the building type, based on floor surface, using the lowest values of $q$ and $q_{b}$, before considered: $2.5 \mathrm{l} / \mathrm{s}$ person and $0.3 \mathrm{l} /\left(\mathrm{s} \mathrm{m}^{2}\right)$;

Method TS2. The air exchange rate is calculated depending on the maximum number of occupants and floor area using the upper values of the parameters $q$ and $q_{b}$, in particular, those corresponding to category I of TS EN16798.

It is worth noting that the two methods refer to the maximum number of occupants and not the actual number. The two methods reported in EN 16798 were compared with a ventilation rate defined with the proposed methodology, characterized by an assessed moderate IAQ $\left(\mathrm{CO}_{2}\right.$ threshold value equal to $1200 \mathrm{ppm})$. The test cases for which a comparison of the three different strategies were tested are those referred to in Table 2 and identified with labels $5 \# 1$ and $4 \# 1$. The characteristics of the rooms are provided in Table 1 . The following relevant elements can be considered:

- $\quad$ actual number of users: 168 (5\#1), 58 (4\#1);

- initial $\mathrm{CO}_{2}$ concentration: 1138 ppm (5\#1), 678 (4\#1);

- external $\mathrm{CO}_{2}$ concentration: 500 ppm (value experimentally measured).

Table 3 reports the values obtained in term of air flow rates for maintaining acceptable values of $\mathrm{CO}_{2}$ concentrations by using three strategies, the two derived from the European Directive based on the maximum occupancy of the classrooms and the one proposed in the paper based on the real estimation of occupation derived by $\mathrm{CO}_{2}$ measurements. With respect to the two situations analyzed, in the first case (classroom 5\#1), when the number of occupants of the room was about $80 \%$ of the maximum occupation (168 vs. 208), the air exchange rate obtained with the proposed strategy and based on the idea of maintaining an acceptable level of IAQ was similar to the one proposed with the lower values of the Technical Standard (TS1). However, if the room was only partially occupied (less than $20 \%$, as in the case of classroom $4 \# 1$ ), the required air exchange rate was much lower than both the values obtained with the Technical Standards with important energy savings. 
Table 3. Comparison among the air flow rate based on technical standards (TS) and with the proposed strategy for two of the classrooms under analysis.

\begin{tabular}{|c|c|c|}
\hline & $\begin{array}{c}\text { Classroom 5\#1 Air Exchange } \\
\text { Rate }\left(\mathrm{m}^{3} / \mathrm{s}\right)\end{array}$ & $\begin{array}{c}\text { Classroom 4\#1 Air Exchange } \\
\text { Rate }\left(\mathrm{m}^{3} / \mathrm{s}\right)\end{array}$ \\
\hline Strategy TS 1 & 0.58 & 0.85 \\
\hline Strategy TS 2 & 2.42 & 3.15 \\
\hline $\begin{array}{l}\text { Proposed strategy (based on the } \\
\text { actual number of occupants) }\end{array}$ & 0.64 & 0.22 \\
\hline
\end{tabular}

Table 4 shows that the strategy based on the control of the number of occupant (students), proposed in the present paper and available if a $\mathrm{CO}_{2}$ monitoring is active, allowed for a reduced air exchange rate in both the analyzed situations with respect to the solutions recommended by the current Technical Standards. In particular, in three of the analyzed cases, for strategies TS1 and TS2, the values of the air exchange rate were higher than those based on the proposed strategy, indicating significant energy requirements. Those last values, estimated as a function of typical outdoor temperature, determines energy saving for mechanical ventilation; the values are reported in Table 4 for a reference indoor temperature of $20^{\circ} \mathrm{C}$ and the actual value of the external temperature measured during the experimental analysis. The proposed strategy determined, in both cases under analysis, a reduction of value of the air exchange rate with respect to the one required according to the Technical Standards and consequently a reduction of the energy use.

Table 4. Energy consumption for air ventilation for the three strategies during a lessons of about $2 \mathrm{~h}$.

\begin{tabular}{ccc}
\hline & Classroom 5\#1 & Classroom 4\#1 \\
\hline Monitoring day and starting hour & Jan 12 & Jan 17 \\
Average external temperature $\left({ }^{\circ} \mathrm{C}\right)$ & 8.0 & 11.9 \\
Ventilation thermal load (Strategy TS 1) $(\mathrm{kWh})$ & 16.7 & 15.7 \\
Ventilation thermal load (Strategy TS $)(\mathrm{kWh})$ & 69.7 & 60.5 \\
Ventilation thermal load (Proposed strategy) $(\mathrm{kWh})$ & 18.4 & 4.2 \\
\hline
\end{tabular}

Figure 8 shows the profiles of $\mathrm{CO}_{2}$ concentration using the three different values of air exchange rates for the two classrooms analyzed using the same periods (minutes) of the monitoring campaign.

In both the figures, $\mathrm{CO}_{2}$ concentration rise was observed in the basic experimental case, for which no mechanical air exchange rate was applied, and $\mathrm{CO}_{2}$ concentration increased monotonically together with the trend observed with the three different values of air exchange rate. It was observed that a good IAQ could be obtained with each of the three strategies (instead, without mechanical ventilation, high values of indoor $\mathrm{CO}_{2}$ were always measured).

Considering the action of a controlled ventilation, in all cases, the level of $1500 \mathrm{ppm}$ was never reached, while the strategies based on the European Directive, TS1 and TS2, determined levels lower than those determined by the proposed strategy. In both cases, strategy TS2 maintained low values of $\mathrm{CO}_{2}$ inside the classrooms but with high energy consumption. 


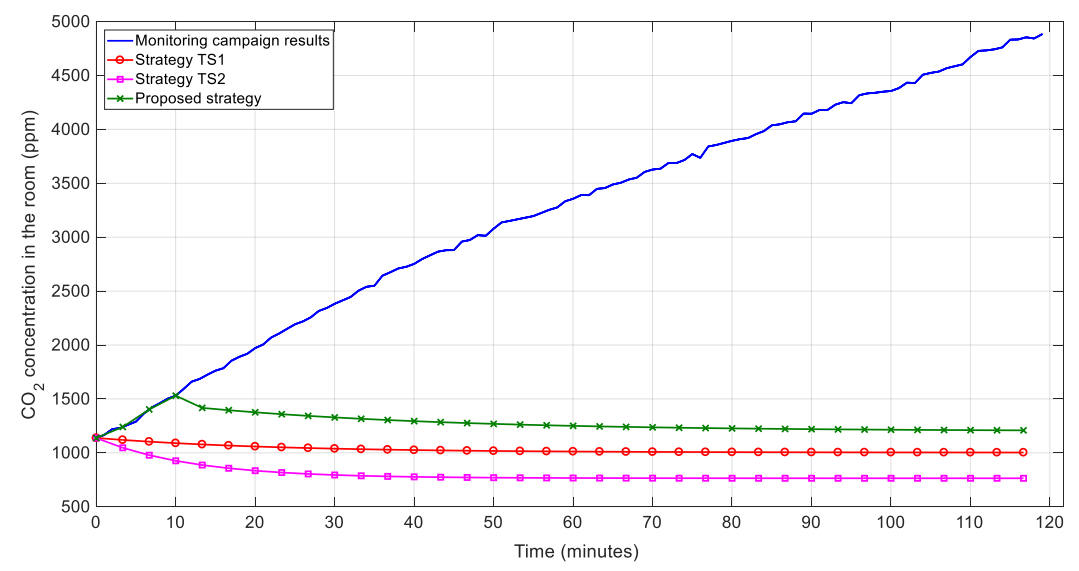

(a) Room 5\#1

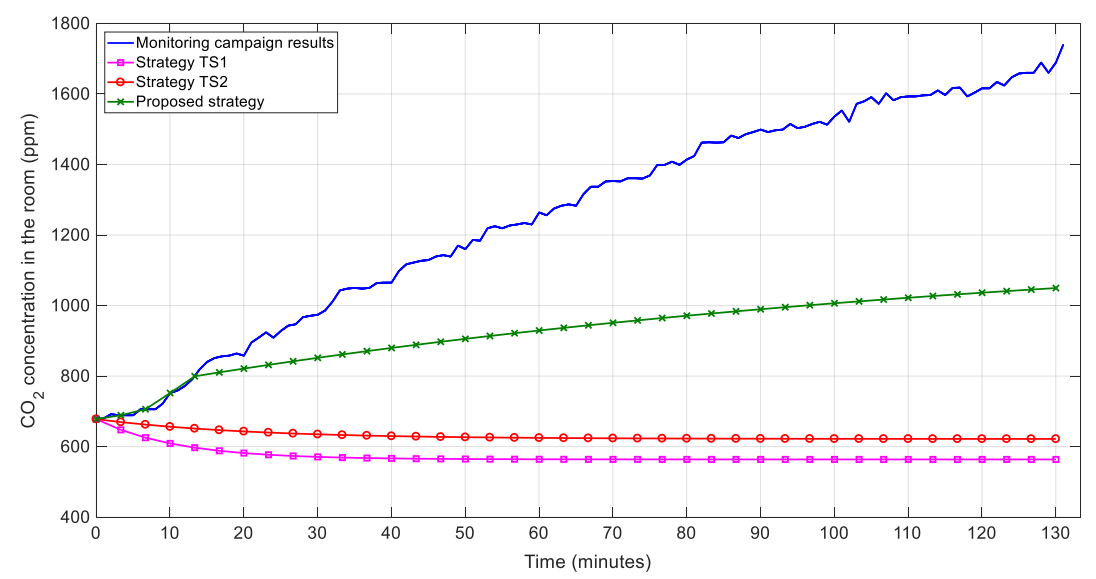

(b) Room 4\#1

Figure 8. Comparison among monitoring results (without mechanical ventilation) and three strategies involving mechanical ventilation for a two hours experience.

\section{Definition Optimal Ventilation Rate Based on a Multi-Objective Approach}

The article should provide a methodology to choose the air change rate inside some classrooms, which are currently ventilated through infiltration and windows opening and where thresholds of $\mathrm{CO}_{2}$ concentration are usually overcome, considering that, in these classrooms, the design ventilation rates are provided for the design value for the number of persons in the room. As university classrooms can accommodate a higher number of students than the actual number of occupants present during a standard lecture (as monitored), the choice of the design ventilation rate would lead to exaggerated ventilation rates (and, consequently, energy consumptions). Thus, the choice of modulating the ventilation rate on the basis of the actual number of occupants can reduce ventilation losses and energy consumptions of the fan and of the HVAC system.

The procedure analyzed in the previous section has a general value; the idea is to detect the presence of students inside the room and then to define a well-defined value of the air exchange rate, thus controlling the operation of HVAC system. This value is not fixed but depends on the actual number of occupants and, in particular, for a defined room, on the specific volume available for each student as well as the $\mathrm{CO}_{2}$ production rate per person specific for the activity performed.

Once the number of occupants is estimated through a short time monitoring $\mathrm{CO}_{2}$ concentration, then the air exchange rate can be calculated on the basis of the required IAQ and energy efficiency standards, thus obtaining maps similar to those reported in Figures 6 and 7. 
The air flow rate can be chosen for a selected threshold of $\mathrm{CO}_{2}$ concentration; all the values in the range between 800 and $1500 \mathrm{ppm}$ can be considered valid and, for a given number of occupants, the minimum air exchange rate to be supplied in the room is provided together with the corresponding ventilation load. This last value functions on external and indoor temperatures.

The occupancy detection guarantees that optimal operation of an HVAC system could be performed and, in particular, the ventilation rate could be the lowest possible required for maintaining a well-defined value of $\mathrm{CO}_{2}$ concentration. Moreover, solutions violating this limit (i.e., $1500 \mathrm{ppm}$ ) are not possible. Thus, in this way, an advanced demand controlled ventilation strategy as a result of the application of a multi-objective optimization strategy can be implemented and defined considering a compromise between maintaining high IAQ and controlled energy consumption.

In this case, it is possible to define an objective function for considering both the objectives using, for example, the "utility function method" available in the textbook by Rao [29] and already tested by Franco and Diaz Vazquez in a different context in [30]. This utility function $F$ can be defined by aggregating in dimensionless form a series of functions $\mathrm{f}_{\mathrm{i}}(\mathrm{x})$, all expressed in dimensionless terms and representative of each objective (e.g., energy consumption, temperature difference with respect to the imposed value, pollutant concentration, relative humidity). It is also possible to consider different weights, $\phi_{I}$, in order to give varying importance to them:

$$
\mathrm{F}=\sum_{\mathrm{i}=1}^{\mathrm{n}} \phi_{\mathrm{i}} \mathrm{f}_{\mathrm{i}}(\mathrm{x})
$$

In a simple case, it is possible to consider two functions, one representing the IAQ based on the control of the maximum permissible value of $\mathrm{CO}_{2}$ concentration and the second one for controlling the energy consumption in connection with the imposed air exchange rate.

IAQ, for example, can be represented by the $\mathrm{CO}_{2}$ concentration in the form of difference with respect to the available standards, while the second indicator accounts for the energy consumption required to maintain the level of $\mathrm{CO}_{2}$ concentration imposed (e.g., $1500 \mathrm{ppm}$ means upper acceptable value of IAQ), according to the European Standards [14].

As for the energy efficiency, the same air flow can be used as an indicator, as it is linearly correlated to the energy consumption due to the ventilation load (see Equation (5)). On one hand, high IAQ would require high ventilation rates to maintain the lowest $\mathrm{CO}_{2}$ concentration inside the classroom. On the other hand, energy efficiency measures would encourage the reduction of air exchange rate in order to reduce energy consumption for ventilation. An optimal strategy choosing the most suitable air flow rate in the analyzed indoor space can be found by both considering the objectives and aggregating them using appropriate weights. If an equal weight is given to both the objectives, such as in this case, $\phi_{1}=\phi_{2}=0.5$. In other cases, different values can be given to $\phi_{\mathrm{i}}$ depending on the importance given to the two concurrent objectives. As example of application of the methodology is the case of the room identified with ID 5 with 122 occupants. The two objectives are, in this case, represented by the following dimensionless indicators:

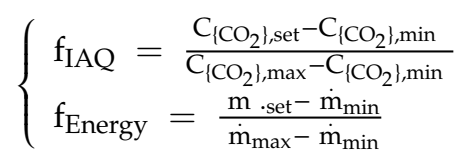

For the first objective, it is considered that the maximum IAQ is obtained with $\mathrm{C}_{\left\{\mathrm{CO}_{2}\right\} \text {, min }}$, set equal to $600 \mathrm{ppm}$, almost equal to the external concentration. The lowest IAQ is obtained with $\mathrm{C}_{\left\{\mathrm{CO}_{2}\right\}, \max \text {, }}$ set equal to $1500 \mathrm{ppm}$, which is also the threshold limit for indoor spaces.

The $\mathrm{C}_{\left\{\mathrm{CO}_{2}\right\} \text {,set }}$ is the effective concentration inside the indoor environment, depending on the air flow rate, which is the object of optimization. As for the second objective, $\dot{\mathrm{m}}_{\min }$ represents the air flow rate associated with minimum ventilation load, which is set equal to $0 \mathrm{~m}^{3} / \mathrm{s}$. Instead, $\dot{\mathrm{m}}_{\text {max }}$ represents the air flow rate associated with the maximum IAQ, which is calculated equal to $4 \mathrm{~m}^{3} / \mathrm{s}$ in this case; 
$\dot{\mathrm{m}}_{\text {set }}$ is the air flow rate, found by means of the utility function method. Both objective functions are singularly optimized when they are close to 0 . In this case, the utility function is:

$$
F=\phi_{I A Q} f_{I A Q}+\phi_{\text {Energy }} f_{\text {Energy }}
$$

In the first case, the two objectives are considered equally important, thus $\phi_{\text {IAQ }}$ and $\phi_{\text {Energy }}$ are 0.5 , and the utility function method gives an optimal value of air flow rate at $1.4 \mathrm{~m}^{3} / \mathrm{s}$ and a $\mathrm{CO}_{2}$ concentration equal to $800 \mathrm{ppm}$. If higher importance is given to energy efficiency, thus maintaining a lower IAQ level inside the room, different weights can be chosen $\left(\phi_{\mathrm{IAQ}}=0.3\right.$ and $\phi_{\text {Energy }}=0.7$ ). In this case, when $\mathrm{CO}_{2}$ concentration is limited at $1000 \mathrm{ppm}$, an optimal air exchange rate of $0.8 \mathrm{~m}^{3} / \mathrm{s}$ is found.

Figure 9 reports the results of the application of the utility function method for $\phi_{\text {Energy }}$ varying the two terms of weight from zero to one (with $\phi_{\mathrm{IAQ}}=1-\phi_{\text {Energy }}$ ) in terms of $\mathrm{CO}_{2}$ concentration at steady-state and optimal air flow rate. The results need to be verified and compared with those obtained in other recent papers about post-processing, such as [31,32].

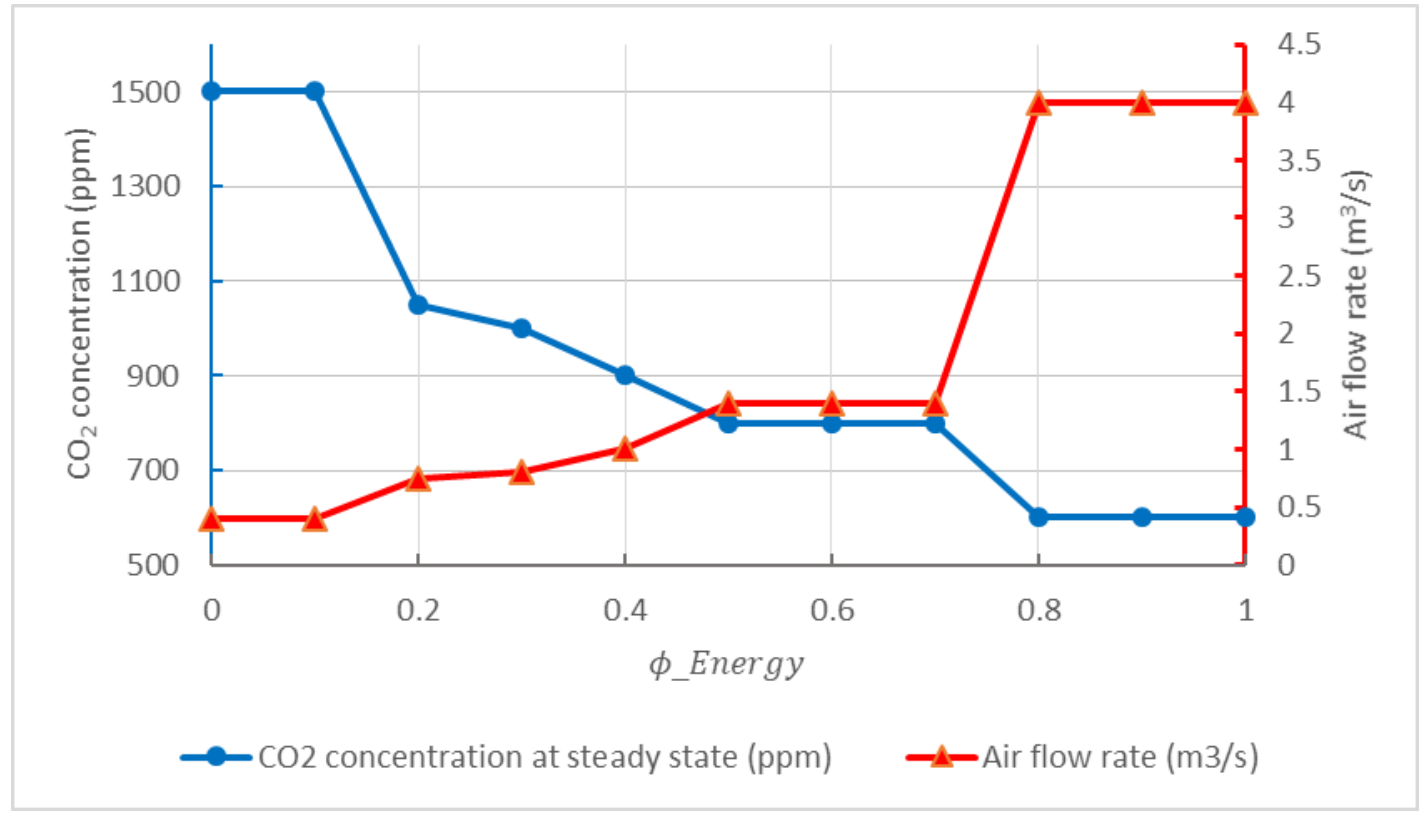

Figure 9. Optimal $\mathrm{CO}_{2}$ concentration and air flow rates applying the utility function method.

\section{Conclusions}

The maintenance of indoor air quality (IAQ) in indoor spaces through mechanically assisted air exchange rate determines a higher value of the energy consumption. For defining an optimal operation of the HVAC system and, in particular, a suitable level of the ventilation rate, knowledge of the number of occupants in the indoor spaces is of fundamental importance.

Based on experimental data acquired in several university classrooms concerning the $\mathrm{CO}_{2}$ concentration rise, the present paper proposes a methodology for correlating the value of air exchange rate required to maintain the maximum permissible $\mathrm{CO}_{2}$ concentration level (1500 ppm) in connection with the real occupation of the same indoor space obtained through the measure of $\mathrm{CO}_{2}$ concentration rise.

The method is based on the knowledge of a specific rate of $\mathrm{CO}_{2}$ production for each person, in this case estimated as $0.2 \mathrm{~L} / \mathrm{min}$. The air flow exchange rates assessed through the proposed method were sensibly lower than those suggested by current Technical Standards and were sensitive to the occupation profile. Considering the two cases, an air exchange rate reduced by a factor 2-3 with respect to the values suggested by European Standards, mainly when the occupation of the room was 
reduced, was sufficient to maintain acceptable values of IAQ conditions with a relevant reduction of the energy consumption.

For the specific $\mathrm{CO}_{2}$ production rate and a specific room tested (two cases were analyzed in particular), integrated maps were provided to find the most suitable air exchange rate, dependent on the number of occupants and on the imposed threshold $\mathrm{CO}_{2}$ concentration value, that needed to be maintained by means of the demand controlled ventilation. In the two cases analyzed in detail, if the occupation was about $70 \%$ of the total, the energy consumption for ventilation was similar to the one obtained with the more conservative strategy suggested by Technical Standard $(18.4 \mathrm{kWh}$ vs. $16.7 \mathrm{kWh}$ ). If the occupation was of the order of $20 \%$ with respect to the maximum permitted, the energy consumption could be reduced in a relevant way ( $4.2 \mathrm{kWh}$ vs. $15.7 \mathrm{kWh})$; the advantage in terms of energy saving appears to be relevant mainly when the occupation is reduced.

Finally, the paper presented a methodology for defining optimum values of the air exchange rates for balancing energy efficiency and user comfort in public buildings through the definition of a dimensionless utility function that considers both $\mathrm{CO}_{2}$ concentration and energy consumption.

Considering that current solutions proposed for improving energy efficiency in public buildings require very accurate energy control, the adaptive solution proposed in the present paper, based on simple measurement of $\mathrm{CO}_{2}$ concentration using commercial sensors, represents a considerable step forward with respect to traditional model-based systems, because it dynamically builds a "just accurate enough" model that could be sufficient to provide optimal decision strategies for operating ventilation rates and HVAC systems in general.

Author Contributions: Conceptualization, A.F.; methodology, A.F.; software, A.F., E.S.; data curation, A.F., E.S.; writing—original draft preparation, A.F. and E.S.; writing — review and editing, A.F. and E.S.; supervision, A.F.; funding acquisition, A.F. All authors have read and agreed to the published version of the manuscript.

Funding: “This research was funded by the University of Pisa (PRA 2018-19, project no. 2018_38)".

Acknowledgments: University of Pisa and School of Engineering are acknowledged for providing the classrooms in which the experimental analysis was carried out. Lorenzo Marchi, former student of the Master Degree in Energy Engineering, is acknowledged for the support given to data analysis.

Conflicts of Interest: The author declares no potential conflict of interest with respect to the research, authorship, and/or publication of this article.

\section{References}

1. European Parliament. Directive 2012/27/EU of the European Parliament and of the Council on Energy Efficiency; European Parliament: Brussels, Belgium, 2012.

2. European Parliament. Directive 2018/844 of the European Parliament and of the Council of 30 May 2018 Amending Directive 2010/31/EU on the Energy Performance of Buildings and DIRECTIVE 2012/27/EU on Energy Efficiency; European Parliament: Brussels, Belgium, 2018; p. 17.

3. Belmonte, J.F.; Barbosa, R.; Almeida, M.G. $\mathrm{CO}_{2}$ concentrations in a multifamily building in Porto, Portugal: Occupants' exposure and differential performance of mechanical ventilation control strategies. J. Build. Eng. 2019, 23, 114-126. [CrossRef]

4. Merema, B.; Delwati, M.; Sourbron, M. Demand controlled ventilation (DCV) in school and office buildings: Lessons learnt from case studies. Energy Build. 2018, 172, 349-360. [CrossRef]

5. Mysen, M.; Berntsen, S.; Nafstad, P.; Schild, P. Occupancy density and benefits of demand-controlled ventilation in Norwegian primary schools. Energy Build. 2005, 37, 1234-1240. [CrossRef]

6. Wachenfeldt, B.J.; Mysen, M.; Schild, P.G. Air flow rates and energy saving potential in schools with demand-controlled displacement ventilation. Energy Build. 2007, 39, 1073-1079. [CrossRef]

7. Simanic, B.; Nordquist, B.; Bagge, H.; Johansson, D. Indoor air temperature, $\mathrm{CO}_{2}$ concentration and ventilation rates: Long-term measurements in newly built low-energy schools in Sweden. J. Build. Eng. 2019, $25,100827$. [CrossRef]

8. Persily, A.K. Evaluating Building IAQ and Ventilation with Indoor Carbon Dioxide. ASHRAE Trans. 1997, 103, 193-204. 
9. McLaughlin, J.E.; King, G.A.; Howley, E.T.; Bassett, D.R., Jr.; Ainsworth, B.E. Assessment of the Cosmet K4B2 portable metabolic system. Med. Sci. Sport Exerc. 2003, 31, S286. [CrossRef]

10. Satish, U.; Mendell, M.J.; Shekhar, K.; Hotchi, T.; Sullivan, D.; Streufert, S.; Fisk, W.J. Is $\mathrm{CO}_{2}$ an indoor pollutant? Direct effects of Low-to-Moderate $\mathrm{CO}_{2}$ Concentrations on Human Decision-Making Performance. Environ. Health Perspect. 2012, 120, 1671-1678. [CrossRef]

11. Myhrvold, A.N.; Olsen, E.; Lauridsen, O. Indoor environment in schools-pupils health and performance in regard to $\mathrm{CO}_{2}$ concentrations. In Proceedings of the 7th International Conference on Indoor Air Quality and Climate, Nagoya, Japan, 21-26 July 1996; pp. 369-371.

12. Mendell, M.J.; Heath, G.A. Do indoor pollutants and thermal conditions in schools influence student performance? A critical review of the literature. Indoor Air 2005, 15, 27-52. [CrossRef]

13. American Society of Heating Refrigerating and Air-Conditioning Engineers (ASHRAE). Ventilation for Acceptable Indoor air Quality; ASHRAE Standard 62.1-2016; ASHRAE: Atlanta, GA, USA, 2016.

14. European Committee for Standardization (CEN). EN 13779_Ventilation for Non-Residential Buildings_Performance for Ventilation And Room Conditioning Systems; CEN: Brussels, Belgium, 2010.

15. Johnson, D.L.; Lynch, R.A.; Floyd, E.L.; Wang, J.; Bartels, J.N. Indoor air quality in classrooms: Environmental measures and effective ventilation rate modeling in urban elementary schools. Build. Environ. 2018, 136, 185-197. [CrossRef]

16. Chan, W.R.; Li, X.; Singer, B.C.; Pistochini, T.; Vernon, D.; Outcault, S.; Sanguinetti, A.; Modera, M. Ventilation rates in California classrooms: Why many recent HVAC retrofits are not delivering sufficient ventilation. Build. Environ. 2020, 167, 106426. [CrossRef]

17. Franco, A.; Leccese, F.; Marchi, L. Occupancy modelling of buildings based on $\mathrm{CO}_{2}$ concentration measurements: An experimental analysis. J. Phys. Conf. Ser. 2019, 1224, 10. [CrossRef]

18. Chenari, B.; Dias Carrilho, J.; Gameiro Da Silva, M. Towards sustainable, energy-efficient and healthy ventilation strategies in buildings: A review. Renew. Sustain. Energy Rev. 2016, 59, 1426-1447. [CrossRef]

19. Szczurek, A.; Maciejewska, M.; Pietrucha, T. Occupancy determination based on time series of $\mathrm{CO}_{2}$ concentration, temperature and relative humidity. Energy Build. 2017, 147, 142-154. [CrossRef]

20. Chauvin Arnoux Metrix. Chauvin Arnoux C.A 1510. Available online: https://catalog.chauvin-arnoux.it/it_ en/c-a-1510.html?__from_store=it_it (accessed on 2 July 2020).

21. Hall, J.E.; Guyton, A.C. Diffusion of Oxygen and Carbon Dioxide through the Respiratory Membrane. In Textbook of Medical Physiology; Saunders Elsevier: Philadelphia, PA, UAS, 2011; pp. 485-494.

22. Leonard, W.R. Measuring human energy expenditure and metabolic function: Basic principles and methods. J. Anthropol. Sci. 2010, 88, 221-230.

23. European Committee for Standardization (CEN). EN 16798-1; Energy Performance of Buildings. Ventilation for Buildings. Part 1: Indoor Environmental Input Parameters for Design and Assessment of Energy Performance of Building Addressing Indoor Air Quality, Thermal Environment, Lighting and Acoustics; CEN: Brussels, Belgium, $2019 ; 82$.

24. Zuraimi, M.S.; Pantazaras, A.; Chaturvedi, K.A.; Yang, H.J.J.; Tham, K.W.; Lee, S.E. Predicting occupancy counts using physical and statistical $\mathrm{CO}_{2}$-based modeling methodologies. Build. Environ. 2017, 123, 517-528. [CrossRef]

25. Wolf, S.; Calì, D.; Krogstie, J.; Madsen, H. Carbon dioxide-based occupancy estimation using stochastic differential equations. Appl. Energy 2019, 236, 32-41. [CrossRef]

26. O'Neill, Z.D.; Li, Y.; Cheng, H.C.; Zhou, X.; Taylor, S.T. Energy savings and ventilation performance from $\mathrm{CO}_{2}$-based demand controlled ventilation: Simulation results from ASHRAE RP-1747 (ASHRAE RP-1747). Sci. Technol. Built Environ. 2020, 26, 257-281. [CrossRef]

27. Nassif, N. A robust $\mathrm{CO}_{2}$-based demand-controlled ventilation control strategy for multi-zone HVAC systems. Energy Build. 2012, 45, 72-81. [CrossRef]

28. Batterman, S. Review and extension of $\mathrm{CO}_{2}$-based methods to determine ventilation rates with application to school classrooms. Int. J. Environ. Res. Public Health 2017, 14, 145. [CrossRef]

29. Rao, S.S. Engineering Optimization: Theory and Practice, 4th ed.; John Wiley \& Sons: Hoboken, NJ, USA, 2009.

30. Franco, A.; Diaz Vazquez, A.R. A Thermodynamic Based Approach for the Multicriteria Assessment of Energy Conversion Systems. J. Energy Resour. Technol. 2006, 128, 346-351. [CrossRef] 
31. Park, J.; Loftness, V.; Aziz, A. Post-Occupancy Evaluation and IEQ Measurements from 64 Office Buildings: Critical Factors and Thresholds for User Satisfaction on Thermal Quality. Buildings 2018, 8, 156. [CrossRef]

32. Baronti, P.; Barsocchi, P.; Chessa, S.; Mavilia, F.; Palumbo, F. Indoor Bluetooth Low Energy Dataset for Localization, Tracking, Occupancy, and Social Interaction. Sensors 2018, 18, 4462. [CrossRef] [PubMed]

(C) 2020 by the authors. Licensee MDPI, Basel, Switzerland. This article is an open access article distributed under the terms and conditions of the Creative Commons Attribution (CC BY) license (http://creativecommons.org/licenses/by/4.0/). 